\title{
CLINICAL VALUE OF SOLUBLE UROKINASE-TYPE PLASMINOGEN ACTIVATOR RECEPTOR (SUPAR) AS A BIOMARKER OF DISEASE ACTIVITY IN BEHCET'S DISEASE
}

\author{
Amal Hassan Rizkㄹ, Walaa Abdelfattah², Arwa O. Al-Shaarawy ${ }^{1}$, Nora Y Elsaid ${ }^{1}$ \\ ${ }^{1}$ Rheumatology and Rehabilitation Department, Faculty of Medicine, Cairo University, Egypt \\ ${ }^{2}$ Clinical and Chemical Pathology Department. Faculty of Medicine, Cairo University, Egypt
}

\begin{abstract}
Background: Behçet's disease (BD) is a chronic multisystemic vasculitic disease of unknown pathogenesis. Diagnosis and disease activity measurement has always been a challenge. Soluble urokinase plasminogen activator receptor (suPAR) is showing an increased utility as a promising diagnostic and prognostic inflammatory biomarker in different systemic inflammatory disorders. Objectives: To study the clinical value of plasma Soluble urokinase plasminogen activator receptor (suPAR) in patients with Behçet's disease, and if it can be used as a measure to disease activity. Methods: According to the International Criteria for Behcet's Disease (ICBD), fifty adult Behçet's disease patients were enrolled in the study, and forty healthy adult subjects were included in a case control study. Enzyme-linked immunosorbent assay was used to obtain quantitative data. Results: The suPAR level was not statistically different between the patients with $B D$ patients and the controls. No correlation was found between suPAR levels and disease activity (BDFAC). Conclusion: Very few studies analyzed the clinical value of suPAR level in patients with $B D$ and its correlation with disease activity. Our results show that SUPAR does not seem to play a role in the disease mechanism of $B D$.
\end{abstract}

Key words: Behçet's disease, suPAR, disease activity, inflammation

\section{INTRODUCTION}

Behçet's disease $(\mathrm{BD})$ is a chronic autoimmune disease characterized by recurrent oral ulcers and other systemic manifestations including genital ulcers, skin lesions, ocular, vascular, neurological, articular, and gastrointestinal disease [1]. Although the pathogenesis of Behçet's disease remains unclear, several mechanisms have been implicated [2]. Many, but not all, clinical manifestations of Behçet's disease are thought to be due to vasculitis.

Different immunological pathways trigger an autoimmune inflammatory reaction within vessels, resulting in vasculitis. Vasculitis in BD is characterized by the involvement of arteries and veins of all sizes [3]. In BD, there are different mechanisms of inflammation that may affect endothelial cells, causing endothelial dysfunction, such as anti-endothelial cell antibodies (AECA) as well as many cytokines [2].

Vascular endothelium has fibrinolytic and anticoagulant properties [4]. When endothelial damage occurs, exposure of the subendothelial collagen activates normal hemostatic response. Fibrinogen binds platelets resulting in platelet aggregation [5]. Once the primary hemostatic plug is formed using platelets, the coagulation pathway is activated. Soon after the start of the coagulation process, the fibrinolysis of the clot is initiated. During the fibrinolysis cascade, Plasmin is a key player. Urokinase-type plasminogen activator (UPA) is secreted from the endothelium. From its name, it activates plasminogen converting it to plasmin. Plasminogen activator inhibitor (PAI) is released from the vessel wall, keeping the fibrinolytic process localized [6].

Urokinase-type plasminogen activator receptor (UPAR) is a cell surface receptor that can bind tightly to urokinase-type plasminogen activator (UPA), inducing clot lysis [7]. A triad formed of UPAR, UPA, and Plasminogen activator inhibitor-1 (PAI-1) performs multiple functions not only related to fibrinolysis but includes degradation of extracellular matrix, and activation of matrix metalloproteinases via activation of the proteolytic cascade. UPAR can achieve some cellular responses that are related to tumor progression and angiogenesis. These responses include cell migration, inhibition of apoptosis and cell differentiation. [8].

Soluble urokinase Plasminogen Activator Receptor (suPAR) results from the cleavage of membrane-bound UPAR, which is released into the plasma, serum, urine, and cerebrospinal fluid [9]. SuPAR is a novel biomarker that has been linked to a variety of systemic inflammatory disorders [7]. It is also expressed by many immunological cells such as monocytes, macrophages, T lymphocytes and endothelial cells [10]. 
High serum levels of suPAR is linked to many inflammatory disorders in which continuous immune system activation is the main pathogenesis. This is the case in tuberculosis [11], HIV [12], acute respiratory distress syndrome [13], malignancies like leukemia, bone, and gastrointestinal tumors [14, 15. 16]. It was also observed in autoimmune diseases such as SLE [17] and RA [18].

SuPAR works as an excellent inflammatory biomarker in all previously mentioned diseases. It shows an in vitro stability through repeated cycles of freezing and thawing [19] and it also shows an insensitivity to diurnal variations [20].

In the persistent journey of finding a marker of activity in Behçet's disease, we postulated that suPAR may serve as a potential disease activity marker. Our aim was to measure the suPAR concentrations in the sera of adult Behçet's disease patients and compare it to normal healthy controls. We also studied the correlation between suPAR levels, disease activity, and clinical manifestations of Behçet's disease.

\section{PATIENTS AND METHOdS}

Fifty consecutively recruited $B D$ patients befitting the International Criteria for Behcet's Disease (ICBD) [21] were enrolled in our study. These patients were recruited from the Rheumatology departments and outpatient clinic, Xxxxx Xxxxxx hospitals. Forty age and sex-matched healthy volunteers served as controls. We excluded patients and controls who had other autoimmune diseases, malignancy, or infection. A written consent was obtained from all patients according to the declaration of Helsinki, and the study was approved by the internal department ethics committee of Rheumatology and Rehabilitation department, as well as the institutional ethics committee approval of the Faculty of Medicine, Xxxxx University, Research Ethics Committee prior to their inclusion in the study. Research ethics committee number I-151015.

A full medical history was obtained from all patients including previous and current medications' history. All patients were thoroughly examined, and the appropriate laboratory tests were carried out. The protocol used for BD management in our departments follows the EULAR recommendations for the management of Behçet's disease [22]. Disease activity was assessed using the Behçet's disease current activity form (BDCAF) score [23].

\section{Serum suPAR determination}

Three milliliters of whole blood were collected using a sterile venipuncture on plain tubes, which was left to clot for 30 minutes at room temperature, then serum separation was carried out by centrifugation at 3000 RPM for 20 minutes. After separation, serum was kept at $-20^{\circ}$ until time of the assay. To perform suPAR assays, enzyme-linked immunosorbent assay (ELISA) (Receptor [PLAUR/UPAR] ELISA Kit, Bioassay Technology Laboratory, Shanghai, People's Republic of China) and microplate readers (Biotek ELx 800, BioTek Instrumentations Inc., Winooski, VT, USA) were used. Catalogue No: E3759Hu. Optical density (OD) was measured under a $450 \mathrm{~nm}$ wavelength, which was carried out within 10 minutes after adding the stop solution. The absorbance of each well was determined, and a blank well was taken as zero. According to the standards' concentrations and the corresponding OD values, the linear regression equation of the standard curve was calculated. Using the OD value of the samples, the final concentration of the corresponding sample was determined. Assay range was $0.05 \mathrm{ng} / \mathrm{ml} \rightarrow 10 \mathrm{ng} / \mathrm{ml}$ and sensitivity was $0.015 \mathrm{ng} / \mathrm{ml}$.

\section{Statistical analysis}

Statistical analysis was performed using Statistical Package for Social Sciences, Version 21.0 (SPSS, Inc., Chicago, III., USA) for Windows. We analyzed continuous variables as mean values \pm standard deviation (SD) or median (range) as appropriate. Rates and proportions were calculated for categorical data., and for categorical variables the differences were analyzed using $x^{2}$ (Chi square) tests. Kolmogorov-Smirnov test of normality was done to assess normality of continues variables before starting the analysis. Differences between continuous variables with normal distribution were analyzed using Student's T-test. For continuous variables without normal distribution, we used non-parametric tests, and the differences were analyzed using the Mann-Whitney U-test. Pearson's correlation was used to examine the correlation between different numerical variables. A p-value $\leq 0.05$ was considered significant.

\section{RESULTS}

The study included 50 BD patients, of whom 44 $(88 \%)$ were males and six (12\%) were females. The subjects had a mean age of $35.7 \pm 8.1$ years, and a mean disease duration of $8 \pm 6$ years. Forty agematched healthy volunteers were included as controls, of which 34 were males and 6 were females (with a mean age of $35.1 \pm 8.9$ years).

Clinical manifestations of the studied BD patients included: 
Oral ulcers, genital ulcers, skin, ocular, articular, vascular, neurological, gastrointestinal, pulmonary, and cardiac manifestations (as shown in table 1).

Table 1. Clinical manifestations of the Behcet's disease patients

\begin{tabular}{|r|l|}
\hline $\begin{array}{r}\text { Clinical manifestations } \\
\mathrm{n}(\%)\end{array}$ & $\begin{array}{l}\text { BD patients } \\
(\mathrm{n}=50)\end{array}$ \\
\hline Oral ulcers & $47(94 \%)$ \\
\hline Genital ulcers & $48(96 \%)$ \\
\hline Eye & $33(66 \%$ \\
\hline Skin & $27(54 \%)$ \\
\hline Articular & $31(62 \%)$ \\
\hline Vascular & $19(38 \%)$ \\
\hline CNS & $16(32 \%)$ \\
\hline GIT & $3(6 \%)$ \\
\hline Pulmonary & $8(16 \%)$ \\
\hline Cardiac & $2(2.1)$ \\
\hline
\end{tabular}

CNS: central nervous system, GIT: gastrointestinal tract

\section{Medical treatment of the studied BD patients}

Of the 50 BD patients, forty-seven (94\%) patients received oral prednisone $(5-20 \mathrm{mg} /$ day $)$, thirty-five $(70 \%)$ patients received colchicine $(0.5-1 \mathrm{mg} /$ day), and 31 (62\%) received Azathioprine (100-150 $\mathrm{mg} /$ day). Twenty-nine (58\%) patients received pulse Cyclophosphamide (750-1000 mg/month) for 6 months, $16(32 \%)$ received Cyclosporine-A (200-300 $\mathrm{mg} /$ day), 15 (30\%) received Methotrexate (17.5-25 $\mathrm{mg} /$ week, subcutaneous), 17 (34\%) received Infliximab (200-400 mg intravenous at 0,2, and 6 weeks, then every 2 months), and 21 (42\%) received warfarin (WARF). The dose was individually adjusted to reach a target international normalized ratio (INR) of 2-3. Thirteen cases $(26 \%)$ received non-steroidal anti-inflammatory drugs and $44(88 \%)$ patients received other medications.

\section{Serum suPAR in the BD patients and controls}

In the present study, the suPAR levels showed no statistical difference between patients with $B D$ and the healthy controls. For patients with $\mathrm{BD}$, the mean suPAR level was $0.2 \pm 0.5 \mathrm{ng} / \mathrm{mL}$ and the mean level of the controls was $0.3 \pm 0.4 \mathrm{ng} / \mathrm{mL}$, with a p-value equal to 0.413 (figure 1).

Serum suPAR in relation to demographic data and smoking in Behçet's disease

No statistically significant correlation was found between serum suPAR and age $(r=0.068$, p-value $=0.638$ ) or gender of the Behçet's disease patients $(p$-value $=0.91) .($ Data shown in table 2$)$.

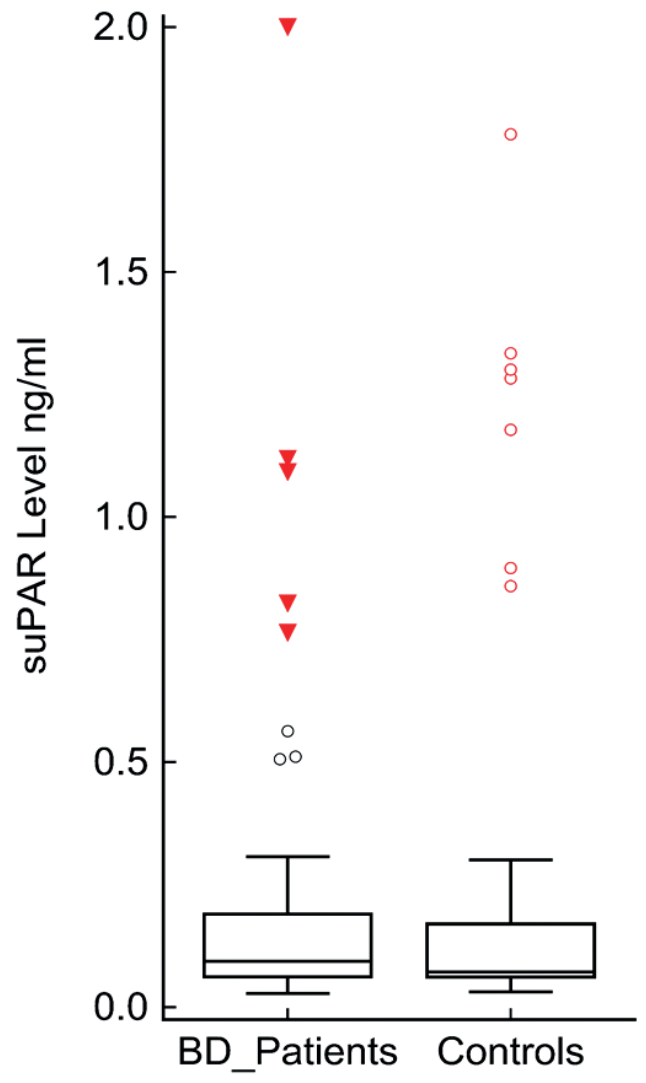

Fig. 1. Comparison between the Behcet's disease patients and the controls regarding the suPAR levels

Table 2. Correlation between suPAR levels and gender and smoking in $B D$ patients

\begin{tabular}{|l|r|l|c|}
\hline \multicolumn{2}{|c|}{ Variables } & $\begin{array}{l}\text { suPAR }(\mathrm{ng} / \mathrm{ml}) \\
\text { mean SD }\end{array}$ & P-value \\
\hline Gender & $M(n=44)$ & $0.19 \pm 0.47$ & 0.91 \\
\cline { 2 - 4 } & $\mathrm{F}(\mathrm{n}=6)$ & $0.17 \pm 0.41$ & \\
\hline Smokers & $\mathrm{Y}(\mathrm{n}=29)$ & $0.22 \pm 0.52$ & \\
\cline { 2 - 4 } & $\mathrm{N}(\mathrm{n}=21)$ & $0.14 \pm 0.36$ & 0.56 \\
\hline Age & $\mathrm{R}=0.068$ & & 0.638 \\
\hline
\end{tabular}

Serum suPAR in different clinical presentations of Behçet's disease

The suPAR was higher in BD patients with oral and genital ulcers as a clinical manifestation (both with a p-value equal to 0.006) (Data shown in table 3).

Correlation of suPAR levels, disease activity (BDCAF), markers of activity, and different laboratory parameters in $B D$ patients

No correlation was found between serum suPAR levels and disease activity or activity markers as ESR or CRP (Data shown in table 4). 
Table 3. Correlation of suPAR levels and different clinical manifestations in $B D$ patients

\begin{tabular}{|c|c|c|c|}
\hline \multicolumn{2}{|l|}{ Variables } & \multirow{2}{*}{$\begin{array}{c}\begin{array}{c}\mathrm{suPAR}(\mathrm{ng} / \mathrm{ml}) \\
\text { mean SD }\end{array} \\
0.06 \pm 0.24\end{array}$} & \multirow{2}{*}{$\begin{array}{r}\text { P-value } \\
0.087\end{array}$} \\
\hline Anemia & $Y(n=17)$ & & \\
\hline & $N(n=33)$ & $0.25 \pm 0.53$ & \\
\hline Oral ulcers & $\begin{array}{l}Y(n=47) \\
N(n=3)\end{array}$ & $\begin{array}{l}0.19 \pm 0.47 \\
0.00 \pm 0.00\end{array}$ & 0.006 \\
\hline Genital ulcers & $\begin{array}{l}Y(n=48) \\
N(n=2)\end{array}$ & $\begin{array}{l}0.19 \pm 0.47 \\
0.00 \pm 0.00\end{array}$ & 0.006 \\
\hline \multirow[t]{2}{*}{ Eye } & $Y(n=32)$ & $0.19 \pm 0.50$ & 0.89 \\
\hline & $N(n=17)$ & $0.18 \pm 0.39$ & \\
\hline \multirow[t]{2}{*}{ Skin } & $Y(n=27)$ & $0.19 \pm 0.52$ & 0.87 \\
\hline & $N(n=23)$ & $0.17 \pm 0.39$ & \\
\hline \multirow[t]{2}{*}{ Articular } & $Y(n=31)$ & $0.27 \pm 0.54$ & 0.06 \\
\hline & $N(n=19)$ & $0.05 \pm 0.23$ & \\
\hline \multirow[t]{2}{*}{ Vascular } & $Y(n=19)$ & $0.16 \pm 0.37$ & 0.73 \\
\hline & $N(n=31)$ & $0.20 \pm 0.51$ & \\
\hline \multirow[t]{2}{*}{ CNS } & $Y(n=16)$ & $0.13 \pm 0.34$ & \\
\hline & $N(n=34)$ & $0.21 \pm 0.51$ & 0.47 \\
\hline \multirow[t]{2}{*}{ GIT } & $Y(n=2)$ & $0.00 \pm 0.00$ & 0.06 \\
\hline & $N(n=47)$ & $0.19 \pm 0.47$ & \\
\hline
\end{tabular}

$\mathrm{Y}=$ Yes, $\mathrm{N}=$ No, suPAR: soluble urokinase plasminogen receptor activator, DM: diabetes mellitus HTN: hypertension, CNS: central nervous system, GIT: gastrointestinal tract. Bold values are significantly different at $p \leq 0.05$

Table 4. Correlation of the suPAR with disease activity, and laboratory investigations in Behçet's disease patients

\begin{tabular}{|l|c|c|}
\hline Variables & $\begin{array}{c}\text { SuPAR level }(\mathbf{n g} / \mathrm{ml}) \\
(\mathbf{r})\end{array}$ & $\begin{array}{c}\text { P-value } \\
(\mathbf{p})\end{array}$ \\
\hline ESR & -0.142 & 0.325 \\
\hline CRP & -0.065 & 0.655 \\
\hline Disease activity & -0.53 & 0.7 \\
\hline Hb & -0.058 & 0.689 \\
\hline TLC & 0.025 & 0.861 \\
\hline PLT & 0.142 & 0.325 \\
\hline
\end{tabular}

\section{Discussion}

Behcet's disease is increasingly encountered within rheumatology clinics. The diagnosis of $\mathrm{BD}$ remains challenging since the initial presentation is nonspecific with no reliable serological tests or imaging tools, rendering the diagnosis of $\mathrm{BD}$ a plainly clinical diagnosis. In addition, there is no standard follow-up tools, which consequently makes the comparison of treatment options and the use of new medications very difficult [24]. Therefore, finding a sensitive biomarker that is linked to the BD pathogenic process or clinical presentations or may serve as a marker of disease activity has always been a dream for every rheumatologist.
Soluble urokinase Plasminogen Activator Receptor (suPAR) is a novel biomarker showing increased utility as a diagnostic and prognostic marker in different systemic inflammatory disorders [9]. The suPAR was shown to be a good marker of inflammation, which also predicts disease and mortality in the general population. The prognostic value of suPAR levels of certain diseases confirms that suPAR is a new promising inflammatory biomarker [25].

In this study, we selected patients with BD who were diagnosed according to International Criteria for Behçet's Disease (ICBD). The serum soluble urokinase plasminogen activator (suPAR) concentrations were measured and compared with those of the healthy controls. Correlation with clinical manifestations and disease activity was done. We found that the suPAR level was not different between the patients with $\mathrm{BD}$ and the controls. No correlation was seen between the suPAR levels and the disease activity (BDFAC) in the BD patients.

As far as we know, the concept of the current study was investigated only twice; one study was done by Birengal and colleagues [26], and the other was by Kurtipek and colleagues [27]. The two studies showed conflicting results. The present study is the first study to investigate the association between suPAR levels and BD on a population other than the Turkish population. Moreover, our study is the first to correlate the biomarker suPAR with different BD manifestations.

The insignificant difference in suPAR levels between the BD patients and the healthy controls, was also demonstrated by Birengal et al. In contrast, the study done by Kurtipek et al., found a significant difference in suPAR levels between the BD and control. This may be attributed to the lack of standardization in choice of patients as BD has a wide spectrum of clinical manifestations. It may also be because of the effect of treatment. The study by Kurtipek et al. had an exclusion criteria of systemic drug intake except colchicine, while most of our patients were on corticosteroids. The effect of drugs on suPAR levels was not thoroughly studied. However, Tamura et al. [28] found that circulating Plasminogen activator inhibitor (PAI-1) - which inhibits Urokinase-type plasminogen activator receptor (UPAR) - is elevated during corticosteroid treatment.

In parallel with the study done by Kuritipek et al., we found no correlation between the suPAR levels and disease activity.

Although suPAR serum levels showed a statistically significant difference in BD patients with oral and genital ulcers when compared with oth- 
er BD clinical manifestations, we could not count on these results as the number of patients with no oral or genital ulcers was very low. Similarly, Birengel et al., concluded that there is no correlation between suPAR levels, age, gender, duration of the disease, clinical manifestations, or disease activity.

The suPAR is considered a fibrinolytic factor which has many inflammatory functions demonstrated by the fact that, increased immune system activation leads to increased serum suPAR levels, which is seen in individuals suffering from various infections, autoimmune diseases, and cancer. In these diseases, the concentration of suPAR correlates negatively with the prognosis of the disease.

As an example, in SLE, suPAR was found to a very useful biomarker of disease prognosis and predicting organ damage [29].

Interestingly, in rheumatoid arthritis (RA), the concentration of suPAR correlated with the number of swollen joints and was associated with disease activity [30].

However, inflammation in BD remains a lowgrade inflammation in most cases, which might explain why estimation of disease activity remains challenging. Disease flares are often unpredictable. Neither their nature nor frequency or duration can be anticipated. Currently, only certain lab tests such as CRP and ESR are considered as markers for disease activity [31].

We believe that although suPAR is an inflammatory biomarker and a predictor of mortality in many diseases, it does not seem to have a big role in BD. $\mathrm{BD}$ keeps its secrets warranting us to work harder to uncover them in future research.

Our study is unique in its design and in exploring the correlation between different manifestations of $\mathrm{BD}$ and the promising suPAR. However, it had some limitations which were: 1) the small number of participants in each group, and 2) the lack of follow-up data due to the cross-sectional manner of the study.

In conclusion, this study showed that no significant difference was seen between suPAR levels in patients with BD and the controls. The suPAR levels may not be directly related to disease activity in BD patients and it is not suggested in the prediction of developing activity in Behçet's disease. However, further prospective studies with larger patient series and follow-up data are needed to determine the difference in suPAR levels among different ethnicities, as well as the correlation between other factors.
Conflict of interest: The authors declare that there is no conflict of interest regarding the publication of this paper.

Funding: This research did not receive any specific grant from funding agencies in the public, commercial, or not-for-profit sectors.

Ethics approval: The patients' written consent was obtained according to the declaration of Helsinki, and the study was approved by the internal department ethics committee of Rheumatology and Rehabilitation department, as well as the institutional ethics committee approval of the Faculty of Medicine, Xxxxx university, Research Ethics Committee prior to their inclusion in the study. Research ethics committee number I-151015.

\section{References}

1. Kokturk A. Clinical and Pathological Manifestations with Differential Diagnosis in Behçet's Disease. Patholog Res Int 2012:690390. Doi:10.1155/2012/690390.

2. Kaufman WS, McNamara EK and Jorizzo JL..Behçet's Disease. Kelley and Firestein's Textbook of Rheumatology 2017 pp.1589-1596.

3. Türsen U. Pathophysiology of the Behçet's Disease. Patholog Res Int. 2012:493015. Doi:10.1155/2012/493015.

4. Iba T and Levy JH. Inflammation and thrombosis: roles of neutrophils, platelets and endothelial cells and their interactions in thrombus formation during sepsis. $\mathrm{J}$ Thromb Haemost.; 2018 Feb;16(2):231-241. PMID: 29193703 Doi: $10.1111 /$ jth.13911

5. Periayah MH, Halim AS and Mat Saad AZ. Mechanism Action of Platelets and Crucial Blood Coagulation Pathways in Hemostasis. International Journal of Hematology-Oncology and Stem Cell Research; 2017,11(4):319-327.PMID: 29340130; PMCID: PMC5767294.

6. Graf C, Ruf W. Tissue factor as a mediator of coagulation and signaling in cancer and chronic inflammation. Thromb Res; 2018Apr;164 Suppl 1: S143-S147. Doi: 10.1016/j. thromres.2018.01.023

7. Jaiswal RK, Varshney AK, Yadava PK. Diversity and functional evolution of the plasminogen activator system. Biomed Pharmacother; 2018, Feb; 98:886-898. Doi: 10.1016/j.biopha.2018.01.029.

8. Ventorp F, Gustafsson A, Träskman-Bendz L et al. Increased Soluble Urokinase-Type Plasminogen Activator Receptor (suPAR) Levels in Plasma of Suicide Attempters. PLoS One; 2015, Oct 9;10(10): e0140052 Doi: 10.1371/journal. pone.0140052. eCollection 2015.

9. Vasarhelyi B, Toldi G, Balog A. The Clinical Value of Soluble Urokinase Plasminogen Activator Receptor (suPAR) Levels in Autoimmune Connective Tissue Disorders. EJIFCC; 2016 Apr 20;27(2):122-9. PMID: 27683525 PMCID: PMC4975228.

10. Desmedt S, Desmedt V, Delanghe JR, et al. The intriguing role of soluble urokinase receptor in inflammatory diseases. Crit Rev Clin Lab Sci; 2017 Mar;54(2):117-133. Doi: doi: 10.1080/10408363.2016.1269310.

11. Indumati V, Vijay V, Krishnaswamy D, et al. Serum levels of soluble urokinase plasminogen activator receptor(suPAR) as a marker of tuberculosis treatment efficacy. Indian J Tuberc; 2017; Jul;64(3):206-211. Doi: 10.1016/j. ijtb.2017.01.012. Epub 2017 Feb 22

12. Sidenius N, Sier CF, Ullum H et al. Serum Level of Soluble Urokinase-Type Plasminogen Activator Receptor Is a Strong 
and Independent Predictor of Survival in Human Immunodeficiency Virus Infection. Blood;2000, 96(13): 4091-95. PMDI: 11110678

13. Geboers DG, de Beer FM, Tuip-de Boer AM, et al. Plasma sUPAR as a prognostic biological marker for ICU mortality in ARDS patients. Intensive Care Med; 2015, 41:1281-90. Doi: 10.1007/s00134-015-3924-9

14. Hildenbrand R, Allgayer $\mathrm{H}$, Marx A et al. Modulators of the urokinase-type plasminogen activation system for cancer. Expert Opin Investig Drugs; 2010,19(5):641-652. Doi:10.1517/13543781003767400.

15. Dass K, Ahmad A, Azmi AS et al. Evolving role of uPA/uPAR system in human cancers. Cancer Treat Rev; 2008; 34:12236. Doi: 10.1016/j.ctrv.2007.10.005.

16. Bene MC, Castoldi G, Knapp W et al. CD87(urokinase-type plasminogen activator receptor), function and pathology in hematological disorders: a review. Leukemia; 2004, 18:394400. Doi: $10.1038 /$ sj.leu.2403250.

17. Qin DD, Song D, Huang J et al. Plasma-Soluble Urokinase-Type Plasminogen Activator Receptor Levels Are Associated with Clinical and Pathological Activities in Lupus Nephritis: A Large Cohort Study from China. Lupus; 2015,24(6): 546-57 Doi: 10.1177/0961203314558857. Epub 2014 Nov 18.

18. Thornton S, Rossing P, Eugen-Olsen J et al. Urokinase plasminogen activator and receptor promote collagen-induced arthritis through expression in hematopoietic cells. Blood Adv. 2017; Mar 21;1(9):545-556. Doi: 10.1182/bloodadvances.2016004002

19. Riisbro R, Christensen IJ, Hogdall C et al. Soluble urokinase plasminogen activator receptor measurements: influence of sample handling. Int. J. Biol. Mark. 16 (2001) 233-239. Doi: 10.1182/bloodadvances.2016004002.

20. Andersen O, Eugen-Olsen J, Kofoed K et al. Soluble urokinase plasminogen activator receptor is a marker of dysmetabolism in HIV-infected patients receiving highly active antiretroviral therapy. J. Med. Virol. 80 (2008) 209-216. Doi: 10.1002/jmv.21114.

21. International Team for the Revision of the International Criteria for Behçet's Disease (ITR-ICBD). The International Criteria for Behçet's Disease (ICBD): a collaborative study of 27 countries on the sensitivity and specificity of the new criteria. J Eur Acad Dermatol Venereol. 2014;28(3):338-347. Doi:10.1111/jdv.12107.

22. Hatemi G, Silman A, Bang D, et al. EULAR recommendations for the management of Behçet disease. Annals of the Rheumatic Diseases, 2008;67: 1656-1662. Doi: 10.1136/ ard.2007.080432.

23. Bhakta B, Hamuryudan V, Brennan $P$ et al. Assessment of disease activity in Behçet's disease. In: Wechsler B, Godeau
P, eds. Excerpta Medica International Congress Series 1037, 611.Amsterdam: Elsevier Science;1993:235-40.

24. Cho SB, Cho S, Bang D. New insights in the clinical understanding of Behçet's disease. Yonsei Med J., 2012, 53(1):3542. Doi:10.3349/ymj.53.1.35

25. Thuno, Macho B and Eugen-Olsen J. suPAR: The Molecular Crystal Ball. Disease markers; 2009, 27(3): 157-72. Doi: 10.3233/DMA-2009-0657.

26. Birengel S, Yalçındağ FN, Yalçındağ A, et al. Urokinase plasminogen activator receptor levels in Behcet's disease. Thromb Res., 2011, Sep;128(3):274-6. Doi: 10.1016/j.thromres.2011.03.003.

27. Kurtipek GS, Kesli R, Akyurek FT et al. Plasma-soluble urokinase plasminogen activator receptor (suPAR) levels in Behçet's disease and correlation with disease activity. Int $J$ Rheum Dis.;2016, Apr;21(4):866-870. Doi:10.1111/1756185X.12873.

28. Tamura Y, Kawao N, Yano M. et al. Role of Plasminogen Activator Inhibitor-1 in Glucocorticoid-Induced Diabetes and Osteopenia in Mice. Diabetes; 2015, Jun; 64(6): 2194-2206. Doi: $10.2337 / \mathrm{db} 14-1192$.

29. Enocsson H, Wirestam L, Dahle C, et al. Soluble urokinase plasminogen activator receptor (suPAR) levels predict damage accrual in patients with recent-onset systemic lupus erythematosus. Journal of Autoimmunity. 2020 Jan; 106:102340. Doi: 10.1016/j.jaut.2019.102340.

30. Helena Enocsson, Tanja Lukic, Michael Ziegelasch et al. Serum levels of the soluble urokinase plasminogen activator receptor (suPAR) correlates with disease activity in early rheumatoid arthritis and reflects joint damage over time. Translational Research, 2021, ISSN 1931-5244, Doi: https:// doi.org/10.1016/j.trsl.2021.02.007.

31. Nowatzky J and Chajek-Shaul T. Biomarkers in Behçet's Disease: Diagnosis and Disease Activity. Int J Clin Rheumatol, 2009, 4(3):271-286. Doi: http://dx.doi.org/10.2217/ijr.09.22.

Submitted: 13.09.2021

$\triangle$ Correspondence address: Nora Yousry Elsaid (N Elsaid)

Lecturer of Rheumatology and Rehabilitation

Faculty of Medicine

Cairo University, Egypt.

Contact number: 01006236171

E-mail: norayousry@kasralainy.edu.eg

Orcid ID: https://orcid.org/0000-0001-9432-2403 